\title{
First senior house officer job: goal or hurdle?
}

\author{
M J GLYNN, H T MILLINGTON
}

To many newly qualified doctors the prospect of applying for their first senior house officer job is daunting and comes at a time when they are concentrating on coping with their preregistration house jobs. The huge numbers of applicants for each job must be equally daunting to their seniors, who may be faced with 100 or more applications for one or two jobs. We have conducted a survey of graduates in our medical school to assess the real difficulty of this first step on the medical career ladder.

\section{Methods}

During two consecutive years (1982 and 1983) all the graduates of the Charing Cross Hospital medical school who were due to complete their second house officer post on 31 July were contacted by telephone six weeks before that date and given a simple verbal questionnaire. This included $(a)$ what was your first choice of senior house officer specialty ? (b) had you obtained a job by 19 June? (c) how many applications did you make? (d) how many times were you shortlisted ? The location of posts obtained was defined as "local" if they were $(a)$ in the Charing Cross Hospital teaching group; $(b)$ in a hospital where the doctor had done either of his preregistration house jobs; $(c)$ in a hospital where the doctor had spent a period of attachment as a student. Those who did not have jobs by 19 June were contacted later by post and asked if they had obtained a permanent job by November and how many more applications had been sent and interviews obtained.

\section{Results}

The number of graduates completing their house jobs in July was 91 in 1982 and 80 in 1983. Several were not actively applying for jobs in the open market. In 1982 these were one dentist, one naval officer, two women about to get married, two studying for part 1 of the fellowship of the Royal College of Surgeons, and 15 taking time off to go abroad. In 1983 they were one dentist, one naval officer, two studying full time, and 11 taking time off to go abroad. The number of doctors who had obtained jobs by June or November is shown in table I together with the number of applications sent and interviews obtained.

The data on first choice of specialty must be interpreted with caution. For example, some doctors choose an accident and emergency job as a prelude to a career in surgery while others choose it as a job giving valuable experience for many subsequent

Charing Cross Hospital, London W6 8RF

M J GLYNN, MB, MRCP, honorary senior registrar

H T MILLINGTON, MB, FRCS, postgraduate subdean

Correspondence to: Dr Glynn. careers. Table II shows the first choice specialty of the new graduates in 1982 and 1983, divided into those who had obtained a senior house officer job by 19 June and those who had not.

TABLE 1-Number of doctors with senior house officer jobs by 19 fune and 1 November and average number of applications and interviews

\begin{tabular}{|c|c|c|}
\hline & 1982 & 1983 \\
\hline Number of doctors registering & 91 & 80 \\
\hline Number actively applying for SHO jobs & 70 & 67 \\
\hline $\begin{array}{l}\text { Number obtaining jobs by } 19 \text { June } \\
\text { Number obtaining jobs by } 1 \text { November }\end{array}$ & $\begin{array}{l}41\left(59^{\circ}{ }_{0}\right) \\
65\left(93^{\circ}{ }_{01}\right)\end{array}$ & $\begin{array}{l}45(67 \%) \\
61(91 \%)\end{array}$ \\
\hline $\begin{array}{l}\text { Average number of applications per doctor: } \\
\text { With job by } 19 \text { June } \\
\text { Without job by } 19 \text { June }\end{array}$ & $\begin{array}{l}5 \cdot 6 \\
9 \cdot 1\end{array}$ & $\begin{array}{r}8 \cdot 7 \\
12.5\end{array}$ \\
\hline $\begin{array}{l}\text { Further applications: } \\
\text { With job by } 1 \text { November } \\
\text { Without job by } 1 \text { November }\end{array}$ & $\begin{array}{r}7 \cdot 4 \\
14 \cdot 6\end{array}$ & $\begin{array}{l}3.7 \\
7.5\end{array}$ \\
\hline $\begin{array}{l}\text { Average number of interviews per doctor: } \\
\text { With job by } 19 \text { June } \\
\text { Without job by } 19 \text { June }\end{array}$ & $\begin{array}{l}1.9 \\
1.0\end{array}$ & $\begin{array}{l}2.5 \\
1.6\end{array}$ \\
\hline $\begin{array}{l}\text { Further interviews: } \\
\text { With job by } 1 \text { November } \\
\text { Without job by } 1 \text { November }\end{array}$ & $\begin{array}{l}2 \cdot 1 \\
3 \cdot 6\end{array}$ & $\begin{array}{l}0 \cdot 8 \\
2 \cdot 0\end{array}$ \\
\hline
\end{tabular}

TABLE II-First choice of specialty of the new graduates

\begin{tabular}{lrrrrrr}
\hline & \multicolumn{2}{c}{ With job by 19 June } & & \multicolumn{2}{c}{ Without job by 19 June } \\
\cline { 6 - 7 } \cline { 6 - 7 } \multicolumn{1}{c}{ Specialty } & 1982 & 1983 & & 1982 & 1983 \\
\hline Medicine & 3 & 9 & & 12 & 6 \\
Surgery & 9 & 9 & & 2 & 1 \\
General practice & 11 & 10 & & 6 & 13 \\
Accident and emergency & 9 & 13 & & 2 & 0 \\
Anaesthetics & 3 & 1 & & 2 & 0 \\
Obstetrics and gynaecology & 3 & 0 & & 1 & 0 \\
Paediatrics & 0 & 1 & & 1 & 0 \\
Psychiatry & 0 & 2 & & 0 & 2 \\
Pathology & 3 & 1 & & 2 & 0
\end{tabular}

Table III shows those doctors who had not obtained a senior house officer job by 19 June in each year by their initial choice of specialty, and the type of job that they finally obtained. The average numbers of applications sent and interviews obtained by doctors choosing medicine, surgery, and general practice rotations as their first choice specialty are shown in table IV.

In 1982,30 out of 65 doctors $(48 \%)$ who had obtained their first senior house officer job by 1 November had done so in a "local" hospital. The corresponding figure for 1983 was 23 out of $61(38 \%)$.

Considering only those who obtained posts in medicine and surgery, in 1982 seven doctors obtained senior house officer posts in district general hospitals (two in medicine and two in surgery) and nine obtained posts in teaching hospitals and postgraduate centres (three in medicine and six in surgery). In 1983, 14 doctors obtained senior house officer posts in district general hospitals 
TABLE III-Final specialty of those doctors who had not obtained jobs in the indicated first choice specialty by 19 fune

\begin{tabular}{|c|c|c|c|}
\hline \multirow[b]{2}{*}{ First choice } & \multicolumn{3}{|c|}{ Final specialty } \\
\hline & 1982 & 1983 & \\
\hline Medicine & $\begin{array}{l}\text { No job } \\
\text { Anaesthetics } \\
\text { Medicine } \\
\text { Accident and emergency } \\
\text { Surgery } \\
\text { General practice }\end{array}$ & $\begin{array}{l}4 \text { Medicine } \\
3 \text { Anaesthetics } \\
2 \text { Accident and emergency } \\
1 \text { Psychiatry } \\
1 \\
1\end{array}$ & $\begin{array}{l}3 \\
1 \\
1 \\
1\end{array}$ \\
\hline Surgery & Surgery & 2 Surgery & 1 \\
\hline General practice & $\begin{array}{l}\text { Accident and emergency } \\
\text { General practice } \\
\text { Geriatric } \\
\text { No job }\end{array}$ & $\begin{array}{l}3 \text { No job } \\
1 \text { Accident and emergency } \\
1 \text { General practice } \\
1 \text { Ear, nose, and throat } \\
\text { Radiotherapy }\end{array}$ & $\begin{array}{l}5 \\
4 \\
2 \\
1 \\
1\end{array}$ \\
\hline Accident and emergency & Accident and emergency & 2 & \\
\hline Anaesthetics & Anaesthetics & 2 & \\
\hline Paediatrics & Paediatrics & 1 & \\
\hline Psychiatry & Psychiatry & 2 Psychiatry & 2 \\
\hline Pathology & Pathology & 2 & \\
\hline
\end{tabular}

TABLE IV-Average number of applications sent and interviews obtained

\begin{tabular}{lcccccc}
\hline & \multicolumn{2}{c}{ Applications } & & \multicolumn{2}{c}{ Interviews } \\
\cline { 2 - 3 } \cline { 5 - 6 } \multicolumn{1}{c}{ First choice } & 1982 & 1983 & & 1982 & 1983 \\
\hline Medicine & 22 & 14 & & 3 & 2 \\
Surgery & 4 & 9.3 & & 1.4 & 2.4 \\
General practice & 8 & 9.3 & & 2 & 1.9 \\
\hline
\end{tabular}

(nine in medicine and five in surgery) and eight obtained posts in teaching hospitals or postgraduate centres (three in medicine and five in surgery).

\section{Discussion}

Doctors do not find it easy to obtain their first senior house officer job and those who are soon successful are sending in between five and eight applications on average. Doctors who experience at least three months' unemployment after registering will have sent in an average of 20 applications (maximum recorded, 50). The number of applications shows that there is no lack of perseverance among the new graduates. The doctors who are unemployed after registering, although often able to undertake locum employment, must reflect on the purpose of all the hard work needed to qualify and register. The figure of about $15 \%$ of newly registered doctors taking time off before seeking senior house officer jobs shows a deliberate decision by a substantial number to delay entry into the difficult postgraduate career ladder.

The synchronisation of most senior house officer jobs to start in August or February exerts further pressure on the applicants since they think that failure to get a job may lead to six months of unemployment. Thus the number of applications put in by each doctor increases and swells the number of applications for each job to high figures. Rather than concentrating the little time available during a busy preregistration job on a few particularly desired jobs, the doctor tends to send applications to every advertised job in the chosen or related specialty. As a result no time is available to do the ground work for particularly desired jobs, work which is now often necessary even to get on the shortlist. The low number of interviews obtained by each doctor, relative to the number of applications sent, suggests that the real difficulty lies in getting on the shortlist.

A possible solution to this problem might be to have a centralised application system, similar to the Universities Central Council for Admissions system, but this would be complicated by the large number of hospitals and authorities concerned. To achieve such a scheme it would be necessary to set up a centralised, and probably computerised, register of all training posts in the National Health Service and of all prospective trainees. While only a few regions and districts have implemented such a register, a feasibility study has shown it to be possible. ${ }^{1}$

While table II suggests that the likelihood of obtaining a senior house officer job immediately is not increased substantially by choosing any particular specialty, table III clearly shows that medicine and general practice were the first choices of all the doctors who were forced into specialties other than their first choice, or who were unemployed for more than three months. In addition table IV shows that the average number of applications sent by doctors choosing medicine as first choice was substantially more than for those choosing surgery or general practice. An initial job in an alternative specialty is, however, no bar to switching back to the original choice later, and indeed further experience and qualifications may be helpful. While the figures in tables II and III may suggest that surgery is relatively easy to enter at senior house officer level, the prospective surgeon should remember the severe bottleneck at registrar level and not expect surgery to be an easy option. The figures for the other specialties are rather too small to draw any conclusions, except to suggest that the relatively small numbers applying to a large specialty such as anaesthetics may show that more doctors should consider this as a first senior house officer post.

The high proportion of doctors obtaining their first senior house officer job in a hospital in which they are known is not surprising, and the applicants should make use of this as much as possible. The quality of a particular job is difficult to define. A surprisingly high proportion of the surgical senior house officer jobs obtained in both years were in district general hospitals, where the facilities and time for study for the primary fellowship of the Royal College of Surgeons are likely to be less, although these doctors may be planning to study for the exam later in their career. The distribution of posts between district general hospitals and teaching or postgraduate centres was approximately equal in the medical jobs, and initial experience in both types of hospital is valuable for a career in hospital medicine.

A few conclusions may be drawn from this survey that may help the preregisrtation house officer in applying for the first senior house officer job.

(1) Concentrate attention on jobs at "local" hospitals.

(2) Start as early as possible to allow as much time as possible to do ground work for particularly desired jobs.

(3) If the doctor's ultimate career objective is in the more specialised subjects such as anaesthetics he or she may be wise to apply to them initially rather than to do some more general jobs first.

The Short report recommended an expansion of the consultant grade but a freeze on any increase in senior house officer posts. ${ }^{2}$ Parkhouse and O'Brien have shown that even with consultant expansion an appropriately designed junior structure would probably indicate a reduction in senior house officer posts if those who enter training are all to have a reasonable chance of achieving their aim. ${ }^{3}$ While consultant expansion has hardly begun, the freeze on senior house officer expansion is widespread, particularly during the current financial and manpower restrictions. This study shows that the first senior house officer job is not easy to obtain: current policies coupled with any further rise in the number of medical students graduating will make it more difficult.

\section{References}

1 Dowie R. An information system for hospital medical and dental training posts and trainees in England and Wales: report of a feasibility study. London: Council for Postgraduate Medical Education in England and Wales, 1984.

2 Social Services Com to the number of doctors and the career structure in hospitals. London: HMSO, 3 Parkhouse J, O'Brien JM. Medical and dental training and staffing in a region-
the long and Short of it. Br Med $\mathcal{f} 1984 ; 288: 1773-5$.

(Accepted 24 May 1985) 